\title{
Remoção de querosene na mistura querosene/água, utilizando bagaço de caju quimicamente modificado
}

\section{Kerosene removal in kerosene/water mixture, using cashew bagasse chemically modified}

\author{
Raimundo Renato de Melo Neto ${ }^{1}$, Camila Jesiele Oliveira Morais ${ }^{2}$, Francisco Klebson Gomes dos Santos $^{3, *}$, Ricardo $^{2}$ \\ Henrique de Lima Leite ${ }^{4}$, Andarair Gomes dos Santos ${ }^{5}$
}

\begin{abstract}
Resumo: Neste trabalho foi avaliada a capacidade de remoção de querosene, de uma emulsão querosene/água, utilizando bagaço de caju quimicamente modificado. Primeiramente foi analisado o efeito do tratamento químico com hidróxido de sódio $(\mathrm{NaOH})$ em diferentes concentrações, uma vez que o tratamento com álcali é capaz de desestruturar a lignina presente no bagaço, a qual dificulta o acesso aos sítios ativos do adsorvente. Foi evidenciado que a concentração de $0,1 \mathrm{~mol} . \mathrm{L}^{-1} \mathrm{de} \mathrm{NaOH}$ mostrou-se eficiente para o tratamento. As simulações de derramamento evidenciaram que, para o bagaço tratado com $\mathrm{NaOH}$, a eficiência de adsorção foi maior $(5,33 \mathrm{~g} / \mathrm{g})$ que para o bagaço sem tratamento $(1,64 \mathrm{~g} / \mathrm{g})$.
\end{abstract}

Palavras-chaves: Adsorção; bagaço de caju; querosene; emulsão.

Abstract: In this research was evaluated the capacity of cashew bagasse chemically modified to remove kerosene from a kerosene/water mixture. First of all it was do a treatment on bagasse with sodium hydroxide $(\mathrm{NaOH})$ it was analyzed at different concentrations, since the alkali treatment is capable to remove the lignin present in the bagasse. The lignin due difficult the adsorbate access on adsorbents sites. It was showed that in a concentration of 0.1 mol. $\mathrm{L}^{-1}$ was efficient for treatment. The simulations showed that the treated bagasse have a higher efficiency $(5.33 \mathrm{~g} / \mathrm{g})$ than the untreated bagasse $(1.64$ $\mathrm{g} / \mathrm{g})$.

Key words: Adsorption; cashew bagasse; kerosene; emulsion.

\footnotetext{
*Autor para correspondência

Recebido para publicação em22/12/2014; aprovado em 06/06/2015

${ }^{1}$ Graduado em Ciência e Tecnologia - DACS/UFERSA, Campus Mossoró-RN, Av. Francisco Mota, 572 - Bairro Costa e Silva, CEP: 59.625-900. E-mail: mtrenato@hotmail.com

${ }^{2}$ Graduada em Ciência e Tecnologia - DACS/UFERSA, Campus Mossoró-RN, Av. Francisco Mota, 572 - Bairro Costa e Silva, CEP: 59.625-900. E-mail: millajesi12@hotmail.com

${ }^{3}$ Eng. Químico, Dr. Eng. Química, Professor - DACS/UFERSA Campus Mossoró-RN, Av. Francisco Mota, 572 - Bairro Costa e Silva, CEP: 59.625-900. Email: klebson@ufersa.edu.br

${ }^{4}$ Eng. Químico, Dr. Eng. de Processos, Professor - DACS/UFERSA Campus Mossoró-RN, Av. Francisco Mota, 572 - Bairro Costa e Silva, CEP: 59.625-900. E-mail: ricardoleite@ufersa.edu.br

${ }^{5}$ Eng $^{a}$ Química, Dr ${ }^{a}$ Eng. Química, Professora - DACS/UFERSA Campus Mossoró-RN, Av. Francisco Mota, 572 - Bairro Costa e Silva, CEP: 59.625-900. Email: andarair@ufersa.edu.br
} 


\section{INTRODUÇÃO}

A descarga de águas residuais contendo óleo no meio ambiente aumenta a cada ano devido à urbanização e desenvolvimento industrial. Os óleos que são encontrados em águas contaminadas podem ser gorduras, lubrificantes, hidrocarbonetos pesados (alcatrão, graxa, óleos crus e óleo diesel) e hidrocarbonetos leves (querosene, querosene de aviação e gasolina). As principais fontes industriais de contaminação incluem refinarias de petróleo, fabricação e usinagem de metais e alimentos processados. A contaminação da água pode ocorrer com o petróleo livre ou flutuante derramado no mar, assim como na forma de emulsões óleo em água.

As tecnologias disponíveis para a remoção do óleo da água incluem: tratamento químico, separação por gravidade, placas coalescedoras paralelas, flotação de gás, separação utilizando ciclone e filtração (Srinivasan et al., 2010).

Nos últimos anos o processo de adsorção tem aparecido como uma técnica de grande potencial para o tratamento de efluentes industriais, principalmente devido à utilização de adsorventes naturais, onde alguns são obtidos de subprodutos da indústria e da agricultura. Muitos estudos têm comprovado a eficiência destes adsorventes para o tratamento de água e efluentes contaminados por óleo, metais pesados e outras substâncias tóxicas.

Para serem utilizados nos processos de adsorção os materiais adsorventes devem apresentar alta capacidade de adsorção, boa flutuabilidade (caso a operação seja em colunas de fluidização), retenção de óleo adequada e, de preferência, ser reutilizável.

A maioria dos adsorventes comercias disponíveis são materiais sintéticos com elevada afinidade ao óleo, devido à sua natureza hidrofóbica. Apesar de suas altas propriedades de sorção, os adsorventes comerciais não são biodegradáveis, fazendo com que eles sejam menos atrativos quando em comparação com alguns adsorventes naturais. A utilização de adsorventes naturais, mesmo sendo sua eficiência e flutuabilidade um pouco menores, quando comparadas com os adsorventes comerciais, devido a sua biodegradabilidade e seu baixo custo, os tornam mais adequados para a tratamento de derramamento de óleo em pequena escala (Radetic et al., 2008).

No Brasil são gerados diversos subprodutos e resíduos agroindustriais em virtude da grande produção agrícola. do país. Entretanto, a disposição dos resíduos gerados nestes setores está se transformando em sério problema ambiental. Apesar de uma parte ser utilizada para fins diversos, uma grande quantidade ainda permanece sem utilização.

O aproveitamento industrial do caju é realizado principalmente na região Nordeste do país, visando basicamente o beneficiamento da castanha e em menor escala, o aproveitamento do pedúnculo. Mesmo considerando o aproveitamento do pedúnculo sob a forma de sucos, doces, geleias, néctares, farinhas e fermentados, só $15 \%$ da produção do pedúnculo é utilizada (Moreira et al., 2009), e após utilização desse pequeno percentual, o bagaço torna-se um resíduo agrícola.

Algumas pesquisas vêm sendo desenvolvidas com o propósito de aproveitamento de resíduos da agroindústria como adsorventes em processos de separação por adsorção.
Sueyoshi et al., (2012) estudaram a ativação física do tronco de palmeira para preparação de carvão ativado. Resultados preliminares mostraram que esse adsorvente tem capacidade de adsorção superior aos adsorventes comerciais assim como alguns resíduos agrícolas. Durante os estudos eles obtiveram uma remoção máxima $105 \mathrm{mg}$ óleo/g de adsorvente e de $405 \mathrm{mg}$ óleo/g de adsorvente para a palma sem tratamento e a palma tratada, respectivamente.

Li et al., (2013) avaliaram a remoção de vários tipos de óleo da água utilizando a casca de uma oleaginosa de origem chinesa tratada quimicamente. Através dos ensaios de adsorção eles obtiveram uma quantidade de remoção de $0,61 \mathrm{~g}$ óleo/g adsorvente. A cinética que melhor correlacionou os dados foi a de pseudo-segunda ordem. Verificou-se também a capacidade de reuso do adsorvente, onde cerca de $80 \%$ do óleo foi removido após sete ciclos de adsorção.

Baseado no exposto, este trabalho tem como objetivo examinar a remoção de hidrocarbonetos leves da água utilizando bagaço de caju com e sem tratamento químico, assim como verificar a eficácia desse durante os ensaios de adsorção.

\section{MATERIAL E MÉTODOS}

Este trabalho foi desenvolvido no Laboratório de Processos Químicos do Centro de Inovação Tecnológica do Semi-Árido (CITED) da Universidade Federal Rural do Semi-Árido (UFERSA).

Foram utilizados: hidróxido de sódio (Micropérolas) P.A. $98 \%$, fornecido por CRQ; acetato de sódio tri-hidratado P.A. 99\%, fornecido por Vetec; ácido acético P.A. 99\%, fornecido por Vetec e querosene da marca King $\odot$. O bagaço de caju foi gentilmente doado pela Universidade Federal do Ceará (UFC).

$\mathrm{O}$ descongelamento do bagaço ocorreu sob refrigeração com temperatura em cerca de $10^{\circ} \mathrm{C}$ durante 8 horas; em seguida o bagaço foi desidratado em estufa (marca Tecnal; modelo TE-394/1), a $60^{\circ} \mathrm{C}$ durante 8 horas. Quando seco, o bagaço de caju foi triturado em multiprocessador (marca Arno; modelo Ar-T30); o pó foi então submetido à separação granulométrica, as peneiras utilizadas foram as de padrão ABNT, e as frações foram separadas de 60 a 325 mesh, nas seguintes subdivisões: 20-59; 60-99; 100-149 e 150-200 mesh; de acordo com estudo feito por Moreira et al., (2009) a granulometria mais eficiente para esse processo de adsorção utilizando bagaço de caju é de 20-59 mesh.

$\mathrm{O}$ bagaço de caju foi tratado quimicamente com $10 \mathrm{~mL}$ de solução de hidróxido de sódio $\mathrm{NaOH}$, variando a concentração de $1 \mathrm{M}$ a $0,1 \mathrm{M}$ e $1 \mathrm{~g}$ do bagaço. Foi feito um estudo variando a concentração de $\mathrm{NaOH}$ de 0,01 a 1 mol.L1 , para que fosse possível analisar o efeito da concentração de hidróxido de sódio na eficiência de remoção de nitrato de água (Melo Neto et al., 2013). Percebeu-se que a partir da concentração de $0,1 \mathrm{M}$ de $\mathrm{NaOH}$ não se obtinha percentuais de remoção maiores, ou seja, essa concentração de álcali era suficiente para desestruturar a lignina presente no bagaço de caju e, consequentemente, aumentar a região de microporos.

As amostras depois de tratadas, foram lavadas com água destilada, e posteriormente com solução tampão com pH 5, pois de acordo com Moreira et al.,(2009) essa é a faixa de $\mathrm{pH}$ ideal para se obter uma boa eficiência no processo de adsorção. Logo após a lavagem o adsorvente foi posto para 
secar a temperatura ambiente, $27^{\circ} \mathrm{C}$, durante 24 horas. Em seguida foi armazenado em dessecador até seu uso (Melo Neto et al., 2013).

A emulsão de óleo em água foi preparada em um agitador da marca Tecnal, modelo Turratec, a uma concentração de 300 ppm de querosene, o qual foi submetido à agitação mecânica a $27000 \mathrm{rpm}$ durante 10 minutos. As emulsões não eram estocadas, preparava-se e em seguida as mesmas eram utilizadas nos ensaios de adsorção.

Os ensaios de adsorção foram realizados em um recipiente de polietileno, bandeja, com capacidade de $3 \mathrm{~L}$.

No recipiente foram adicionados $1,5 \mathrm{~L}$ da emulsão preparada; em seguida foram adicionados $15 \mathrm{~g}$ de bagaço de caju tratado, e deixados em contato durante 1 hora; o recipiente foi coberto com filme PVC para evitar perdas por evaporação.

Os ensaios foram realizados a uma temperatura de $20^{\circ} \mathrm{C}$.
Após $1 \mathrm{~h}$ foram coletadas e analisadas amostras do sobrenadante.

Após a separação de fases, uma alíquota da fase oleosa foi retirada e submetida à análise espectrofotométrica a 232 $\mathrm{nm}$; este comprimento de onda foi determinado por varredura das amostras. O valor de absorbância encontrado neste comprimento de onda foi convertido em concentração.

\section{RESULTADOS E DISCUSSÃO}

As amostras foram analisadas em um espectrofotômetro da marca Thermo Scientific, modelo Evolution 600 UV-VIS.

A Figura 1 ilustra a curva de calibração utilizada na análise de espectrofotometria. A Figura 2 mostra a quantidade de hidrocarboneto removida utilizando o bagaço de caju tratado com hidróxido e sódio e sem tratamento químico.

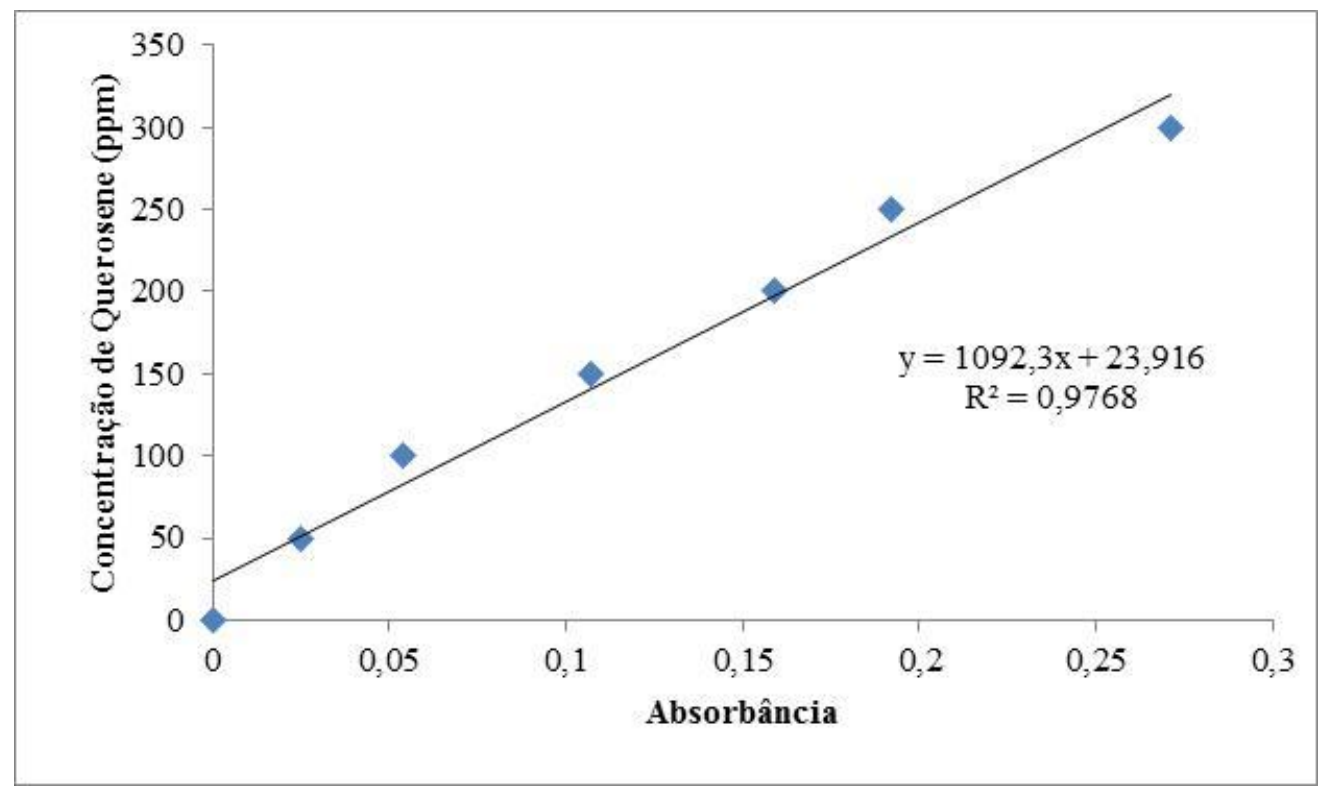

Figura 1. Curva de calibração utilizada na análise de espectrofotometria. Mossoró, RN, 2015.

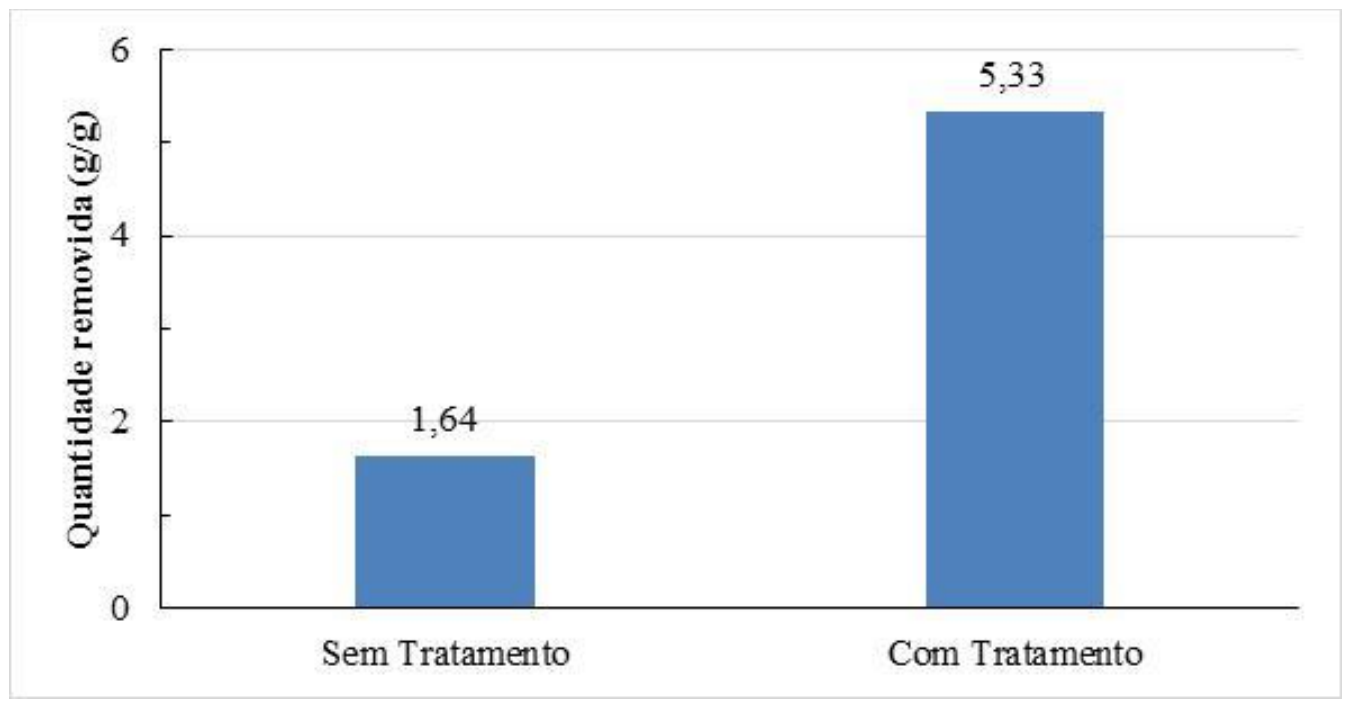

Figura 2. Efeito do tratamento do bagaço de caju com álcali. Mossoró, RN, 2015. 
Analisando a Figura 2 pode-se perceber que o tratamento químico propiciou uma maior remoção de hidrocarbonetos, 5,33 $\mathrm{g}$ de hidrocarbonetos/g de bagaço tratado, enquanto que o bagaço sem tratamento removeu apenas 1,64 g/g. O tratamento químico remove a lignina (composto orgânico vegetal) que recobre os sítios ativos do bagaço de caju, promovendo assim uma maior adsorção (Moreira et al., 2009).
A Tabela 1 mostra diferentes resíduos agrícolas utilizados como adsorventes de hidrocarbonetos, em diferentes trabalhos, onde avaliaram a eficiência de remoção através da quantidade máxima de adsorbato adsorvido por grama de adsorvente. Na Figura 3 foi plotado um gráfico da quantidade máxima de adsorbato adsorvido por grama de adsorvente $(\mathrm{g} / \mathrm{g})$, em função do material adsorvente utilizado nas diferentes pesquisas.

Tabela 1 - Adsorventes utilizados na separação O/A e suas respectivas capacidades de adsorção.

\begin{tabular}{llll}
\hline Adsorvente & Adsorbato & Qe $(\mathrm{g} / \mathrm{g})$ & Referência \\
\hline Fios de Lã & Diesel & 10,5 & Radetic et al., (2008) \\
Fios de Lã & Óleo Cru & 12,5 & Radetic et al., (2008) \\
Fios de Lã & Óleo Vegetal & 14,5 & Radetic et al., (2008) \\
Atapaulgita & Óleo Cru & 0,40 & Sueyoshi et al., (2012) \\
Lã Natural & Óleo Lubrificante & 0,17 & Rajacovic et al., (2008) \\
Quitosana & Óleo Cru & 0,10 & Srinivasan \&Viraraghavan, (2010) \\
Casca de Noz & Óleo Cru & 0,08 & Srinivasan \&Viraraghavan, (2010) \\
Bagaço de caju & Querosene & 1,64 & Este trabalho \\
Bagaço de caju tratado & Querosene & 5,33 & Este trabalho \\
\hline
\end{tabular}

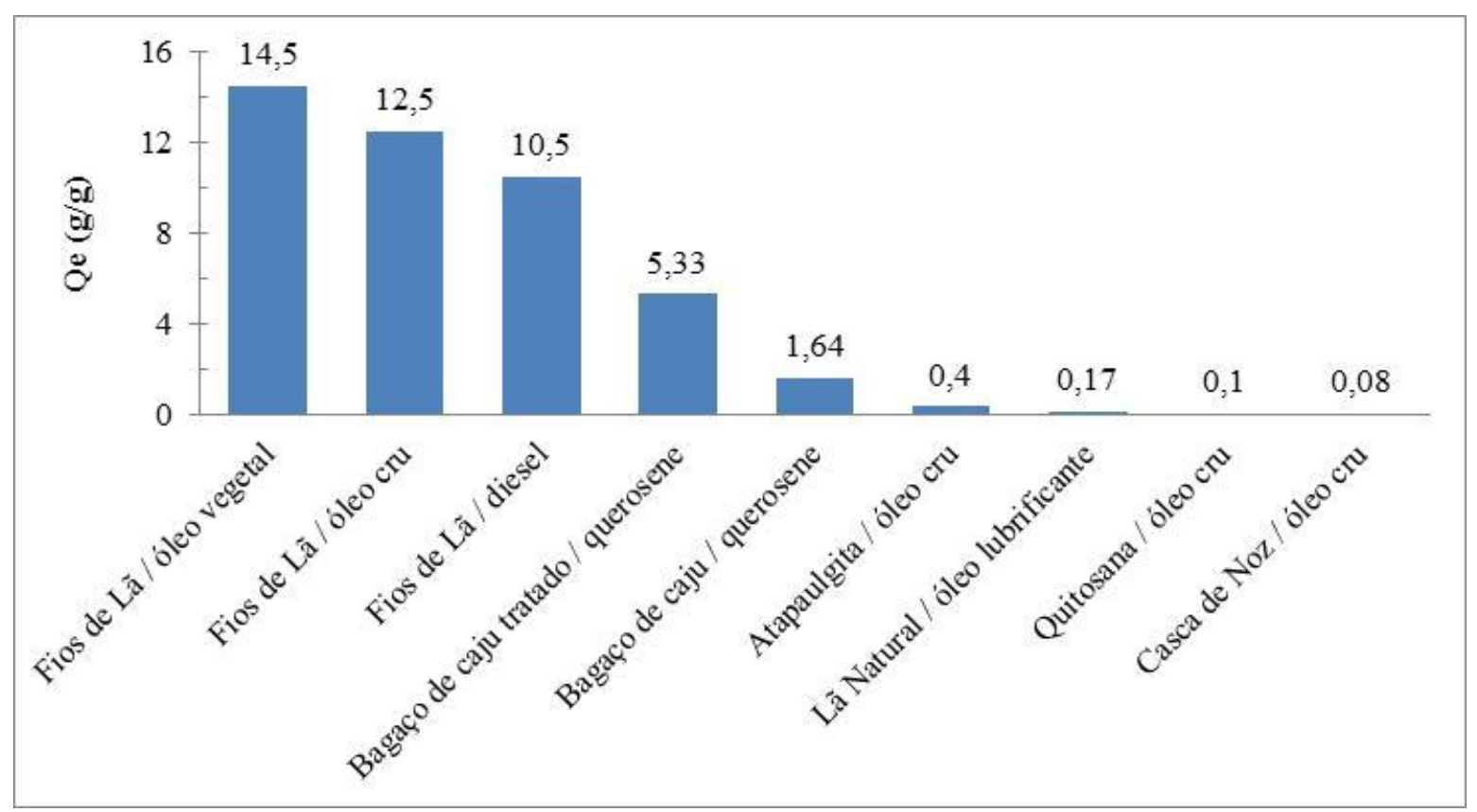

Figura 3. Quantidade máxima de adsorbato $\left(\mathrm{Q}_{\mathrm{e}}\right)$ adsorvido por grama de adsorvente, variando os tipos de adsorventes e adsorbatos. Mossoró, RN, 2015.

Analisando a Figura 3 pode-se perceber que os adsorventes do tipo fios de lã chegam a uma capacidade máxima de adsorção de $14,5 \mathrm{~g} / \mathrm{g}$ na adsorção do óleo vegetal, obtendo também bons resultados para óleo cru e diesel, 12,5 e 10,5, respectivamente, segundo Radetic et al., (2008).

Utilizando bagaço de caju, com e sem tratamento com álcali, chegou-se a 5,33 e 1,64 g/g, respectivamente. Esses valores são superiores aos de outros trabalhos que utilizam atapaulgita, lã natural, quitosana e casca de noz, para remover adsorbatos de óleo cru e óleo lubrificante, apresentados em outros trabalhos (Rajacovic et al., 2008; Srinivasan e Viraraghavan, 2010; Sueyoshi et al., 2012).

\section{CONCLUSÕES}

Com base no estudo realizado nesse trabalho pode-se afirmar que o bagaço de caju, por possuir um baixo custo e uma boa eficiência de remoção, pode ser considerado um material eficaz para o tratamento de água contaminada por hidrocarbonetos leves. Os ensaios de adsorção evidenciaram que o bagaço de caju tratado obteve uma maior capacidade de remoção, 5,33 g/g, em relação ao bagaço sem tratamento, $1,64 \mathrm{~g} / \mathrm{g}$.

\section{AGRADECIMENTOS}

Ao CNPq/UFERSA. 


\section{REFERÊNCIAS BIBLIOGRÁFICAS}

ALI, I.; ASSIM, M.; KHAN, T. A. 2012. Low cost adsorbents for the removal of organic pollutants from wastewater. Journal of Environmental Management, 113, 170-183.

CARBERY, J.B.; TWARDOSSKI, O.J.; EBERHART, D.K. 1977. Clay adsorption treatment of non-ionic surfactants in wastewater. Journal of Water Pollution Control, 49, $452-459$.

LI, J. LUO, M.; JIAN, M.; LI, C.; WANG, W.; ZU, Y.; FU, Y. 2013. Fu Oil removal from water with yellow horn shell residues treated by ionic liquid. Bioresource Techonology, 128, 673-678.

MELO NETO, R. R; SANTOS, F. K. G; LEITE, R. H. L; NÓBREGA, G. A. S; RIOS, R. B. 2013. Remoção de nitrato da água utilizando bagaço de caju quimicamente modificado. Revista Verde de Agroecologia e Desenvolvimento sustentável, 8, 4, 0816.

MOREIRA, S. A.; SOUSA, F. W.; OLIVEIRA, A. G.; NASCIMENTO, R. F.; BRITO, E.S. 2009. Remoção de metais de solução aquosa usando bagaço de caju. Química Nova, 32, 1717-1722.

PINHO, L. X. 2009. Aproveitamento do resíduo do pendúnculo de caju (Anacardiumoccidentale $L$.) para alimentação humana. Dissertação de Mestrado, Universidade Federal do Ceará.

RADETIC, M.; ILIC, V.; RADOJEVIC, D.; MILADINOVIC, R.; JOCIC, D.; JOVANCIC, P. 2008. Efficiency of recycled wool-based nonwoven material for the removal of oils from water. Chemosphere, 70, $3,525-530$

RAJAKOVI'C-OGNJANOVI'C, V.; ALEKSI, G.; RAJAKOVI'C, L. 2008. Governing factors for motor oil removal from water with different sorption materials. Journal of Hazardous Materials, 154, 563558.

SANTOS, M. F. R. 2011. Elaboração do technology road map para biorrefinaria de produtos da lignina no Brasil. Tese de Doutorato, Universidade Federal do Rio de Janeiro.

SRINIVASAN, A.; VIRARAGHAVAN, T. 2010. Oil removal from water using biomaterials. Bioresource Techonology, 101, 6594-6600.

SUEYOSHI, M.; AL-MAAMARI, R. S.; JIBRIL, B.; TASAKI, M.; OKAMURA, K.; KUWAGAKI, H.; YAHIRO, H.; SAGATA, K.; HAN, Y. 2012. Preparation and characterization of adsorbents for treatment of water associated with oil production. Journal of Analytical and Applied Pyrolysis, 97, 80-87. 